\title{
Lidar observations of atmospheric boundary layer structure and sea spray aerosol plumes generation and transport at Mace Head, Ireland (PARFORCE experiment)
}

\author{
Gerard J. Kunz and Gerrit de Leeuw \\ Physics and Electronics Laboratory, Netherlands Organization for Applied Scientific Research, The Hague, Netherlands
}

Edo Becker

BP Chemicals Ltd., Hedon, UK

Colin D. O’Dowd

Department of Physical Sciences, University of Helsinki, Helsinki, Finland

Received 16 August 2001; revised 15 November 2001; accepted 5 December 2001; published 11 September 2002.

[1] A scanning backscatter lidar was used to measure the depth and structure of the coastal atmospheric boundary layer and the evolution of primary aerosol (sea spray) plumes produced by breaking waves during the New Particle Formation and Fate in the Coastal Environment (PARFORCE) campaign at the Mace Head Atmospheric Research Station (Ireland) in September 1998 and in June 1999. The PBL structure was observed to vary from a single-layer well-mixed structure to multilayered structures. Comparison with in situ aircraft measurements of temperature and humidity exhibited good agreement. Using the lidar in the scanning mode allowed two-dimensional profiling over a spatial scale of $10 \mathrm{~km}$, revealing significant primary aerosol plumes produced by breaking waves, particularly in the surf zone and at high wind speeds on the open sea. The initial plume heights were some tens of meters and evolved to hundreds of meters while transported over only a few kilometers from the source. The plumes were traceable to distances of more than $10 \mathrm{~km}$ down wind from the source. INDEX TERMS: 3360 Meteorology and Atmospheric Dynamics: Remote sensing; 3394 Meteorology and Atmospheric Dynamics: Instruments and techniques; 0305 Atmospheric Composition and Structure: Aerosols and particles (0345, 4801); KEYWORDS: laser radar, scanning lidar, mixed layer, aerosol plumes, breaking waves, backscatter

Citation: Kunz, G. J., G. de Leeuw, E. Becker, and C. D. O’Dowd, Lidar observations of atmospheric boundary layer structure and sea spray aerosol plumes generation and transport at Mace Head, Ireland (PARFORCE experiment), J. Geophys. Res., 107(D19), 8106, doi:10.1029/2001JD001240, 2002.

\section{Introduction}

[2] Generally, the marine atmosphere is considered to comprise a well-mixed and neutrally stratified planetary boundary layer (PBL) in which conserved variables such as the potential temperature and specific humidity remain constant with height. Similarly, it is often assumed that species such as aerosols and trace gases are also well mixed with height. This simplification, however, has been shown to be inaccurate through many field experiments (e.g., the Atlantic Stratocumulus Transition Experiment (ASTEX) [Albrecht et al., 1995] and the Aerosol Characterization Experiments, ACE1 [Bates et al., 1998] and ACE2 [Raes et al., 2000]) and consequently leads to difficulties in interpreting ground based field data. In the recent ACE2 clean and polluted Lagrangian studies in which an air parcel

Copyright 2002 by the American Geophysical Union. 0148-0227/02/2001JD001240 was sampled over a 30-hour period, large changes in boundary layer height and structure were observed. During one of these studies (the clean Lagrangian), the boundary layer height was observed to decrease $50 \%$ concomitant with an increase in wind speed. The net effect of these two meteorological changes was to increase the particle concentration in the accumulation mode (and consequently the cloud condensation nuclei) by a factor of $2-3$ [Johnson et al., 2000; Hoell et al., 2000]. In contrast, during the polluted Lagrangian study, the boundary layer height, and thus, mixing volume, increased by about a factor of 2 while aerosol concentration reduced by a similar amount due to entrainment from the free troposphere (FT) [Osborne et al., 2000; Hoell et al., 2000]. These two cases illustrate clearly the importance of determining the structure of the PBL as its effect on aerosol and gas concentrations can be very large.

[3] Very often, there is limited availability of data on the vertical structure of the boundary layer due to the difficul- 


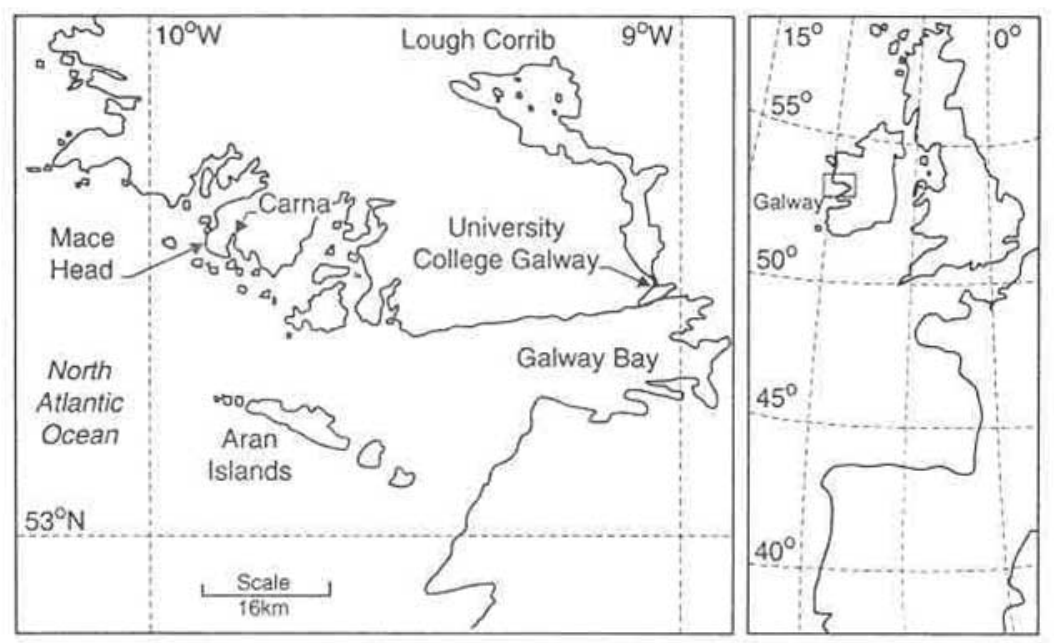

Figure 1. The Mace Head Atmospheric Research station is located in the west of Ireland near Galway at position $53^{\circ} 20^{\prime} \mathrm{N}, 09^{\circ} 54^{\prime} \mathrm{W}$ (see the overview map on the right). The Galway area is enlarged to show more detail in the left-hand side figure.

ties and cost of acquiring such data. Typically, PBL structure is determined through the release of radio sondes at infrequent intervals, by sonar [see e.g., Stull, 1988, section 10.3.2; Schotland, 1985] or by deploying research aircraft at even less frequent intervals and significantly higher costs. Lidar (light detection and ranging) offers an opportunity of continuous PBL observation. Lidars have been used for atmospheric studies since many years. Examples on the application of lidar for studies on the temporal or spatial variation of atmospheric parameters were presented by, e.g., Sasano et al. [1980], Melfi et al. [1985, 1989], or Goldsmith et al. [1998]. Lidar scans in either elevation or azimuth are used for studies on spatial inhomogeneities of aerosol backscatter or water vapor concentrations, or to measure wind speed and direction with incoherent systems [e.g., Eloranta et al., 1975; Kunkel et al., 1977; Sasano et al., 1982a, 1982b; Hooper and Eloranta, 1986; Nakane and Sasano, 1986; Hooper et al., 1996]. Results from a scanning water vapor lidar have been published by, e.g., Cooper et al. [1992], Eichinger et al. [1994], Hagelberg et al. [1998], and Eichinger et al. [1999]. Studies of the three dimensional behavior of atmospheric structures are carried out by a combination of horizontal and vertical scans with the lidar. With this method a large volume in the atmosphere over an area of several tens of square kilometers can be probed within a short time. Pioneering work with this technique was carried out at the University of Wisconsin, USA [cf. Eloranta and Forrest, 1992; Schols and Eloranta, 1992; Piironen and Eloranta, 1995, 1996].

[4] The current study reports on the use of a lidar system for observations of the PBL structure and the generation and evolution of plumes of sea salt aerosol generated by waves breaking in the surf zone, and at elevated wind speed also at open sea. The measurements were made during campaigns undertaken in September 1998 and in June 1999 at the Mace Head Atmospheric Research station at the western coast of Ireland. They were undertaken in support of studies of the formation of new particles at coastal sites due to tidalrelated nucleation events, in the framework of the EU- funded New Particle Formation and Fate in the Coastal Environment (PARFORCE) project [O’Dowd, 1999].

\section{Experiment}

[5] An extensive suite of aerosol, gas and meteorological measurements was deployed during the PARFORCE experimental campaigns [cf. O'Dowd, 2002a, 2002b] for an overview). This section provides descriptions of the lidar. Other instrumentation used for the analysis of the lidar data, in particular of boundary layer profiles near Mace Headonboard the Meteorological Research Flight Hercules C-130 is described by O'Dowd [1999].

\subsection{Experimental Location}

[6] The Mace Head Atmospheric Research Station (cf. Jennings et al. [1991, 1998] or McGovern et al. [1996] for detailed descriptions) is located on the western coast of Ireland $\left(53^{\circ} 20^{\prime} \mathrm{N}, 09^{\circ} 54^{\prime} \mathrm{W}\right)$, see the map in Figure 1 . In the immediate vicinity there are four small and uninhabited islands in the bay near the station: South Macdara's Island at $2.5 \mathrm{~km}$ offshore, Croaghnakeela at $4.3 \mathrm{~km}$, Illaunagroagh More at $3.8 \mathrm{~km}$ and Illaunagroagh Beg at $4.2 \mathrm{~km}$. The area of the islands varies between $0.1 \mathrm{~km}^{2}$ and $1.0 \mathrm{~km}^{2}$.

[7] The western coast of Ireland is quite inhomogeneous [O'Dowd, 2002a, 2002b] with Mace Head Atmospheric Research Station located on a peninsula. This midlatitude station is subject to prevailing westerly winds associated with the easterly tracking cyclonic systems of the North Atlantic. Hence the station is usually exposed to maritime air which is considered representative of background North Atlantic marine air.

\subsection{Backscatter Lidar Measurements}

[8] Lidar is a widely used remote sensing technique for atmospheric research [see e.g., Collis, 1966; Measures, 1984]. A lidar consists in principle of a pulsed laser and an optical receiver, with associated electronics. The laser pulse is emitted into the atmosphere and laser light back- 
scattered by aerosol particles and molecules is received with a telescope that focuses the light onto a photo detector. The time-resolved detector signal is recorded with a digital oscilloscope and further processed. Because the laser pulse is short with a small cross-section, very small volume sections along the laser path in the atmosphere are consecutively probed.

[9] During PARFORCE a so-called biaxial, quasi-monostatic backscatter lidar with direct detection was used to measure profiles of the atmospheric volume backscatter coefficient. The terms "biaxial" and "quasi-monostatic" imply that the transmitter and the receiver are geometrically separated but built together in a compact unit.

[10] The transmitter in the lidar used during the PARFORCE 1999 experiments was a $1.06 \mu \mathrm{m}$ laser (Quantel Brilliant) with an energy of $200 \mathrm{~mJ}$ in a pulse with a duration of $8 \mathrm{~ns}$, and a maximum repetition rate of $20 \mathrm{~Hz}$ (during PARFORCE 1998, a 20 mJ, 4 Hz system was used). The short-term stability (over several minutes) of this laser is of the order of $0.1 \%$ and the long term stability (over the hours) is of the order of $2 \%$. The $8 \mathrm{~ns}$ laser pulse can provide a spatial resolution of $1.2 \mathrm{~m}$. The receiver was a telescope with a diameter of $20 \mathrm{~cm}$ and an avalanche photodiode in the focal plane with a dark noise level of about $0.5 \mathrm{nW}$ and a signal bandwidth of $30 \mathrm{MHz}$. The separation between the axes of the laser and the receiver was $25 \mathrm{~cm}$, which implies that the scattering volume at short distances from the lidar cannot be completely observed by the receiver. Hence the lidar signal is only reliable after a certain range, the crossover range. For the TNO lidar the cross over range is about $200 \mathrm{~m}$. A commercial $100 \mathrm{MHz}$ analogue logarithmic amplifier was used between the analogue detector output and the transient recorder to suppress the dynamic range of the signal amplitude. The output of this amplifier was fed into an 8 bits, $200 \mathrm{MHz}$ analogue to digital converter and stored for off-line processing.

[11] The components in the lidar system are calibrated on a regular base. The laser stability, mentioned above, is $2 \%$, the uncertainty due to the detector is $10 \%$, the pre-and log amplifier each have an uncertainty of $5 \%$, the uncertainty in the transmission optical elements is $20 \%$, in the A/D converter $5 \%$. This leads to an overall uncertainty in the calibration, i.e., the statistical sum of the individual errors, of $20 \%$.

[12] Eye safety was seriously considered, among others, by calculating the safe distance of the lidar following the rules given by the European standard International Electrotechnical Commission (IEC) 825 [IEC, 1984] and the American standard ANSI Z136 [American National Standards Institute, 1993], and by continuously monitoring the area by the operator and with a video system. The safe distances for a $220 \mathrm{~mJ}$ system are $2.0 \mathrm{~km}$ for single shot exposure, $2.4 \mathrm{~km}$ for 0.25 second exposure, $3.8 \mathrm{~km}$ for 1 second exposure and $10 \mathrm{~km}$ for $30 \mathrm{~min}$ exposure (calculated with ETI Beamsafe, a commercial program based on the ANSI Z136). The system was not operated when ships, aircraft or people were in the direct vicinity of the lidar.

\subsubsection{Signal Processing and Data Presentation}

[13] The signal received from beyond the crossover range is proportional to the atmospheric volume backscatter coefficient, as well as to the energy of the emitted light pulse and the area of the receiver. For relatively clean atmospheres the lidar is commonly described by the single scatter lidar model:

$$
P(R)=E \frac{c}{2} \frac{A}{R^{2}} T_{\text {opt }} \beta(R) e^{-2 \int_{0}^{R} \alpha(x) d x}+n^{\prime}(R)+O^{\prime},
$$

where:

$P(R)=$ received power as a function of range in $\mathrm{W}$;

$R=$ range in $\mathrm{m}$;

$E=$ energy of the laser pulse in $\mathrm{J}$;

$A=$ area of the receiver in $\mathrm{m}^{2}$;

$T_{\text {opt }}=$ transmission of the optics [-];

$c=$ speed of light in $\mathrm{m} \mathrm{s}^{-1}$;

$\alpha(R)=$ spatial volume extinction coefficient in $\mathrm{m}^{-1}$;

$\beta(\mathrm{R})=$ spatial volume backscatter coefficient in $\mathrm{m}^{-1} \mathrm{sr}^{-1}$;

$n^{\prime}(R)=$ signal noise expressed in terms of $\mathrm{W}$;

$O^{\prime}=$ signal offset expressed in terms of $\mathrm{W}$.

[14] Equation (1) only applies to ranges larger than the crossover range and for ranges which are large compared to the physical length of the laser pulse. The volume backscatter and extinction coefficients are atmospheric parameters that are determined by the properties of the atmospheric targets (aerosols and molecules).

[15] Correction of the lidar signal, equation (1), for signal offset $O^{\prime}$, geometric attenuation $\left(1 / R^{2}\right)$ and application of the values for the physical constant $(c)$ and for the system factors $\left(E, A, T_{o p t}\right)$ results in $S(R)$, further referred to as the attenuated atmospheric volume backscatter profile:

$$
S(R)=\beta(R) e^{-2 \int_{0}^{R} \alpha(x) d x}+n(R)
$$

where:

$n(R)=$ remaining noise term in the signal in $\mathrm{m}^{-1} \mathrm{sr}^{-1}$.

[16] The first term on the right-hand side of equation (2) describes the volume backscatter profile, attenuated by the path integrated extinction coefficient. Note that geometric correction implies that also the noise term is multiplied by $R^{2}$ and thus increases with range.

[17] Neither the backscatter profile nor the extinction profile can a priori be inverted from equation (2). Commonly, a second relation between the backscatter and the extinction coefficient is assumed to derive an integral equation in either of the two quantities. Solving for this equation requires a boundary condition, i.e., the extinction coefficient at a certain range [see e.g., Hitschfeld and Bordan, 1954; Klett, 1981; Kunz, 1983; Kovalev, 1995] or the transmission losses over a certain range interval [see e.g., Fernald et al., 1972; Weinman, 1988; Kunz, 1996]. (Other methods have been proposed in the last decades [see e.g., Potter, 1987; Ackermann, 1997; Kunz, 1999], but no general solution is available.) Because such extra information is not available, in this contribution the lidar results will be presented in terms of the system-independent atmospheric attenuated volume backscatter profiles $S(R)$ given by equation (2) such as proposed by Platt [1979]. When the atmospheric extinction is negligible, they are equivalent to the backscatter profiles.

[18] The lidar data is presented in false color, using a color scale ranging from purple for small values of $S$ to red for large values, following the order of colors in the rainbow. Upper and lower limits vary for each case to provide optimum contrast. Very low values are represented in black 
and white represents values larger than the maximum value of the selected scale.

[19] The gradual change in color with increasing distance from the lidar is not only an atmospheric effect but might also be caused by cross talk from the intense currents in the laser power supply into the very sensitive electronics of the detector unit.

\subsubsection{Lidar Operational Modes}

[20] During the PARFORCE experiments, the TNO backscatter lidar was mounted in a van that was parked near the shoreline at a height of about $8 \mathrm{~m}$ above mean sea level. From this position, the lidar had a free field of view over the ocean in a sector of about $130^{\circ}$. A computer-controlled platform with an adjustable scan speed from $0.5^{\circ}$ to $75^{\circ}$ per second was used to scan the lidar in azimuth and elevation.

[21] Different types of measurements were carried out during PARFORCE: (1) in a fixed horizontal direction, parallel and perpendicular to the wind, (2) under a fixed elevation angle, (3) horizontal scans and (4) vertical scans either parallel or perpendicular to the wind. After processing, the results were presented in false color images where the atmospheric attenuated volume backscatter coefficient is color-coded. Data from horizontal scans, measured in a polar coordinate system, were transformed to a rectangular coordinate system and projected as plane position indicators (PPI) images over a map of Mace Head and environment. In a similar way, data from the vertical scans were transformed to range to height indicators (RHI) images. To assure that every pixel in the Cartesian coordinate system was filled, each pixel was projected to the nearest measured data point in the polar coordinate system. Redundant data points at short ranges were skipped and missing data points at larger ranges were filled using a zero-order interpolation routine. The data presented in the following sections were measured with a radial resolution of $12 \mathrm{~m}$ (data sampling interval of $80 \mathrm{~ns}$ ) and an angular resolution of better than $0.1^{\circ}$.

\subsection{Airborne Measurements}

[22] Airborne measurements, undertaken with the U.K. Meteorological Research Flight C-130 Hercules, and aimed at exploring the spatial scales of coastal nucleation events, were conducted over 4 days overlapping with the intensive field campaign in 1999. The aircraft was equipped with a broad range of instrumentation [cf. O'Dowd, 1999] of which the vertical variations of the temperature and humidity are relevant for comparison with the lidar results. Detailed descriptions of most instruments are given, for example, by Rogers et al. [1995] and Martin et al. [1997].

\section{Results}

\subsection{Boundary Layer Structure}

[23] The primary objective for using the lidar during the PARFORCE experiments was to provide the depth and evolution of the atmospheric boundary layer. The heights of the boundary layer and cloud bases were estimated from lidar measurements at fixed elevation as well as from vertical scans with the lidar. In this study we define the PBL height as the height of the inversion level separating the free troposphere (FT) from the boundary layer. In cloud-free situations, a strong aerosol gradient usually occurs across the inversion, with lower concentrations in the FT. Hence the top of the PBL was determined from the lidar measurements as the height where a sudden decrease in the lidar signal strength occurred. Alternative definitions are given by, e.g., Melfi et al. [1985], Hooper and Eloranta [1986], and Steyn et al. [1999].

[24] Often various layers can be discerned in the lower few kilometers of the atmosphere. Since during PARFORCE most gas and aerosol measurements were made close to the surface from $10 \mathrm{~m}$ and $22 \mathrm{~m}$ high towers, the Layer Adjacent to the Surface (referred to as LAS in the following) is of particular importance. An example is shown in section 3 (second vertical scan), where the LAS exists within the PBL, and it is the height of the LAS that is presented when multiple layers were observed. The layers are detected by virtue of variations in aerosol concentrations between them, and thus differences in the attenuated backscatter coefficient. The layers may be residual layers, resulting from the formation of internal boundary layers with different thermodynamic structure, or the formation of nocturnal boundary layers [cf. Stull, 1988, section 1.6]. Under the influence of turbulent mixing, the layers may rise and merge; thus the structure may disappear during the day and a single extended layer may result. The detailed analysis of the physics leading to multilayered structures is outside the scope of this paper, which is focused on lidar observations of these phenomena. Figure 2 shows that large variations can occur during the day with often a low surface layer inversion present during the morning increasing in depth throughout the day.

\subsubsection{Fixed Elevation Angle Mode}

[25] The usefulness of the lidar for determining boundary layer height in a single location, but during extended periods of time, is illustrated in Figure 3 with data from the 1998 PARFORCE experiment for Julian Day (JD) 267 (24 September 1998). On this day, the lidar was operated under a fixed elevation angle of $34^{\circ}$, thus allowing acquiring data on the vertical structure of the boundary layer from a height of $100 \mathrm{~m}$. The maximum height from which data were obtained with this elevation angle and the time base resolution used, was $800 \mathrm{~m}$. Data were collected every hour during $5 \mathrm{~min}$. Measurements were started at 0734 UTC and continued until 1845 UTC. The results in Figure 3 illustrate the short-term variability in structure along with significant changes over periods of hours. During the first measurement (0734 UTC), the PBL inversion level was of the order of $300 \mathrm{~m}$ above sea level, but also indicating variability of the order of $50 \mathrm{~m}$ in the vertical. At this time, the PBL appears decoupled into two layers, with the LAS situated in the lower $150-200 \mathrm{~m}$. Note further the increase in the attenuated atmospheric volume backscatter coefficient with height, which could possibly be ascribed to increasing humidity resulting in particle growth. The next measurement, at 0808 UTC, shows much lower attenuated atmospheric volume backscatter coefficients, and a transparent layer over a 200-250 $\mathrm{m}$ deep LAS in which the aerosol particles are poorly mixed. By 0952 UTC this situation has changed and the attenuated atmospheric volume backscatter profile indicates a PBL inversion at a height increased to about $600 \mathrm{~m}$, with a complex internal structure and significantly different aerosol content. The plume structure in the LAS indicates convective mixing. At 1007 UTC a convective boundary layer is observed with plumes originating at 


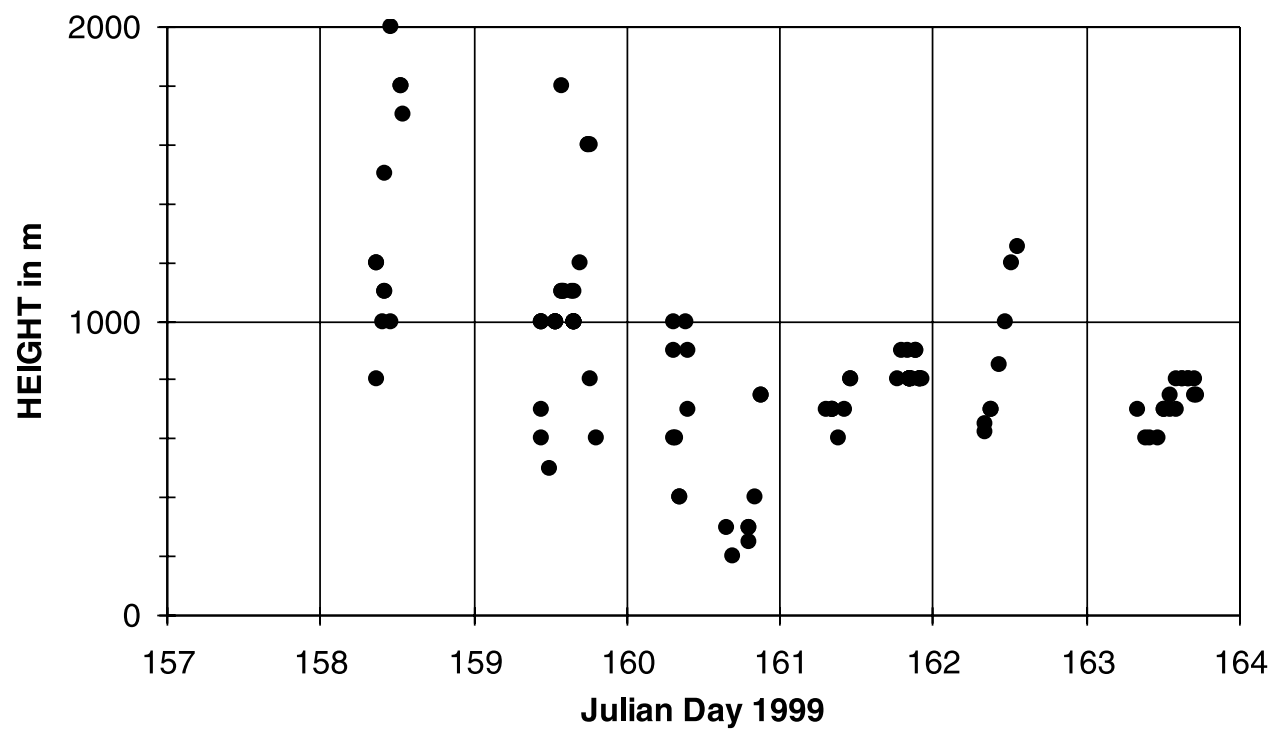

a

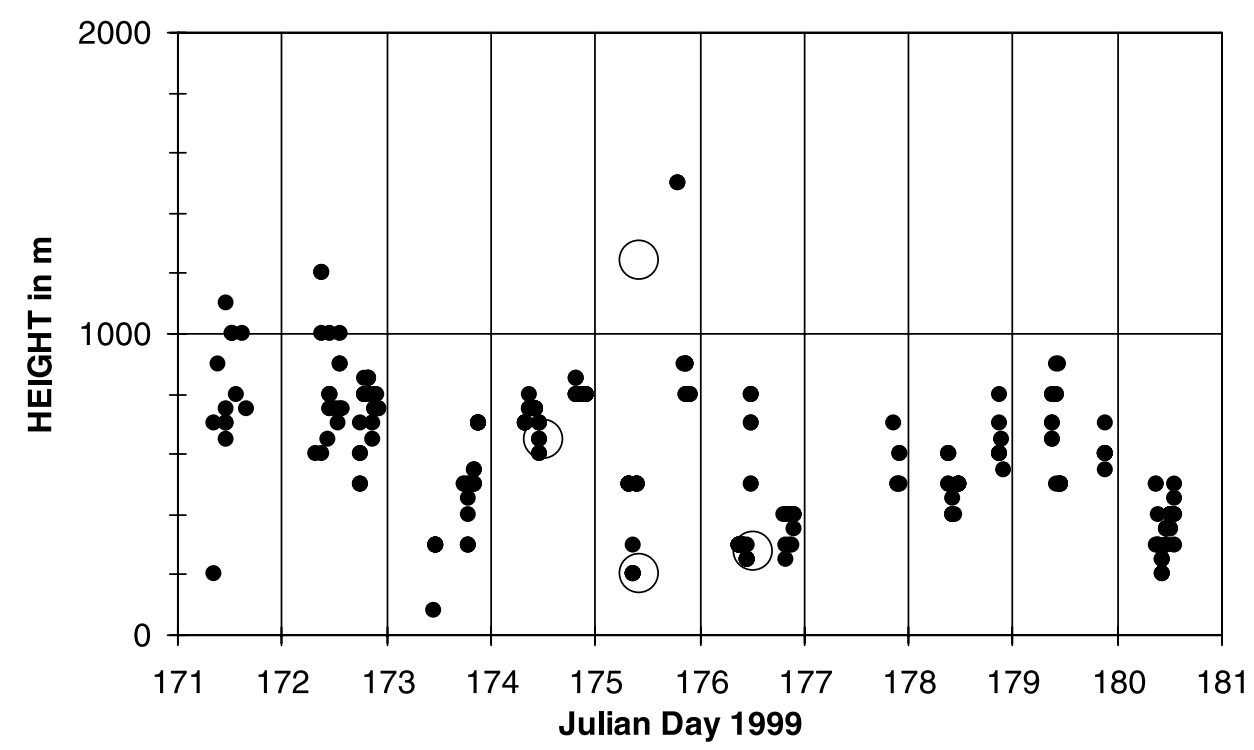

$\mathrm{b}$

Figure 2. Heights of lower layers (LAS; see section 3.1) derived from lidar observations (•) compared with boundary layer heights derived from airborne measurements (O) during the 1999 PARFORCE experiment. (a) Period from JD 157-164 (6-13 June 1999). (b) Period from JD 171-181 (20-30 June 1999). Note that the apparent discrepancy between the airborne derived boundary layer height $(1200 \mathrm{~m})$ at JD 175.4 is due to the fact that for the lidar, only the heights of lower layers are shown; a second layer was observed with the lidar at $1200 \mathrm{~m}$.

the lowest level that could reliably be observed with the lidar. White patches at the top indicate high attenuated atmospheric volume backscatter coefficients, likely due to the onset of cloud formation. The convective structure is more pronounced by 1107 UTC, with very clear plume structures. Between 1300 and 1400 UTC these convective plumes are seen to rise up to at least the maximum height of $800 \mathrm{~m}$ observed by the lidar on this day. Large variability occurs over short timescales. In the measurement at 1504 UTC, clouds are prominent and the attenuated atmospheric volume backscatter coefficients increase up to cloud base. However, as the clouds mask the upper layers, no conclusion on the
PBL depth can be taken from this plot except when there are wholes in the cloud deck. By 1650 UTC, when convection had subsided, the plumes appear smaller and the top of the convective layer has decreased down to approximately $400 \mathrm{~m}$. 3.1.2. Vertical Scanning Mode

[26] While the fixed elevation mode allows continuous measurements of PBL evolution at a single location, the vertical scanning mode allows one to determine the instantaneous two-dimensional structure of the PBL over horizontal distances of up to $10 \mathrm{~km}$. Examples of boundary layer structure over a $5 \mathrm{~km}$ spatial scale are illustrated in Figures $4 \mathrm{a}$ and $5 \mathrm{a}$. The figures show vertical scan results 

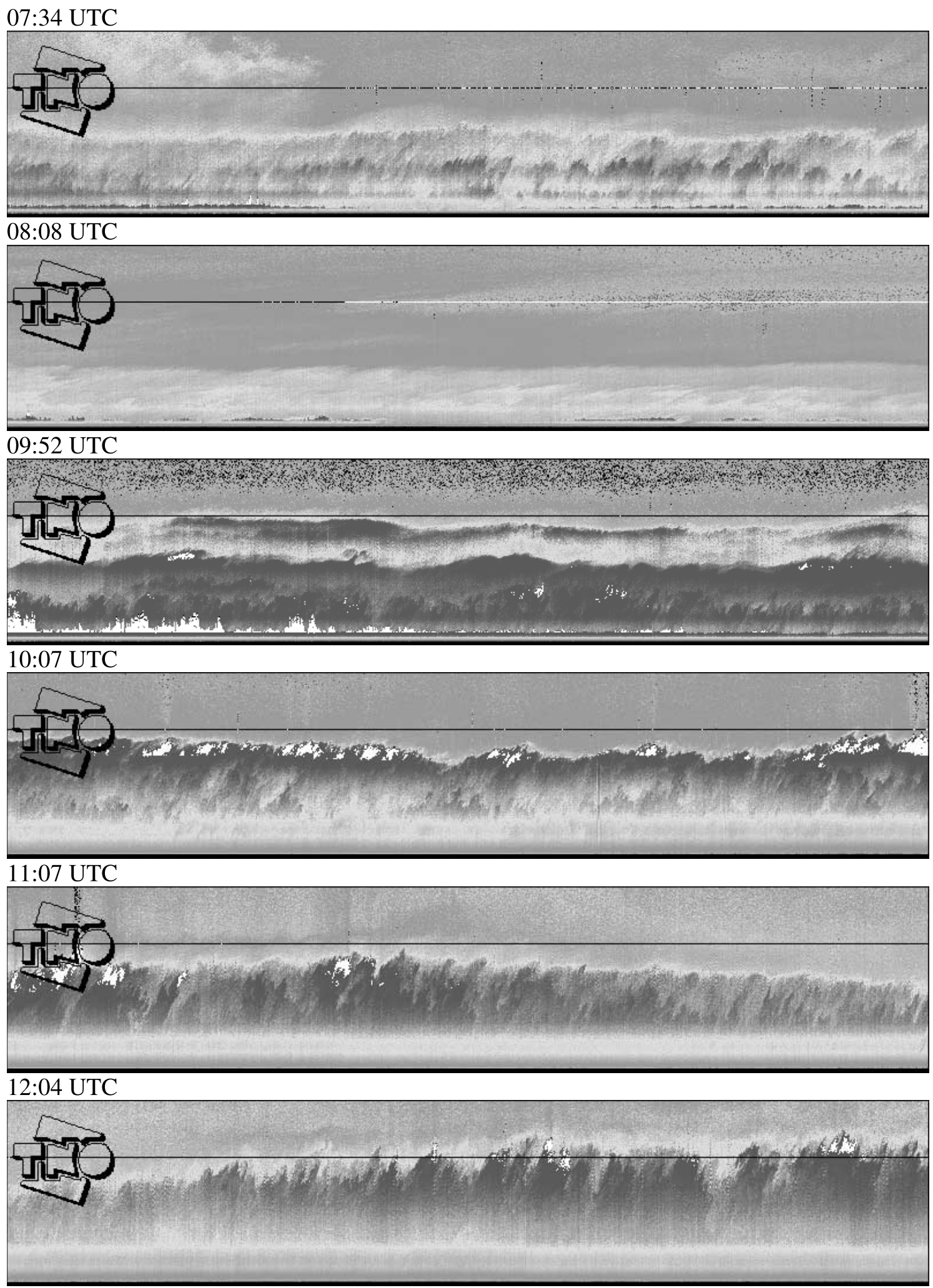

Figure 3. Boundary layer evolution on JD 267 (24 September 1998) between 0734 and 1845 UTC. Shown are time series, each recorded during $5 \mathrm{~min}$, of attenuated atmospheric backscatter profiles $S(R)$ (in $\mathrm{m}^{-1} \mathrm{sr}^{-1}$ ) (equation (2)), in a set of 13 images. The start time is indicated on the top of each figure. The values of the attenuated atmospheric volume backscatter coefficients are indicated by the color, with a scale for $\log [\mathrm{S}(\mathrm{R})]$ ranging from -7.1 (purple) to -5.1 (red) following the order of the colors in the rainbow. Black refers to values of $\log [S(R)]$ smaller than $-7.1 \log \left(\mathrm{m}^{-1} \mathrm{sr}^{-1}\right)$, and white refers to values larger than $-5.1 \log \left(\mathrm{m}^{-1} \mathrm{sr}^{-1}\right)$. Vertical scale: $500 \mathrm{~m} / \mathrm{div}$. The signal below about $100 \mathrm{~m}$ is attenuated due to the crossover function of the lidar (see section 2.2). 


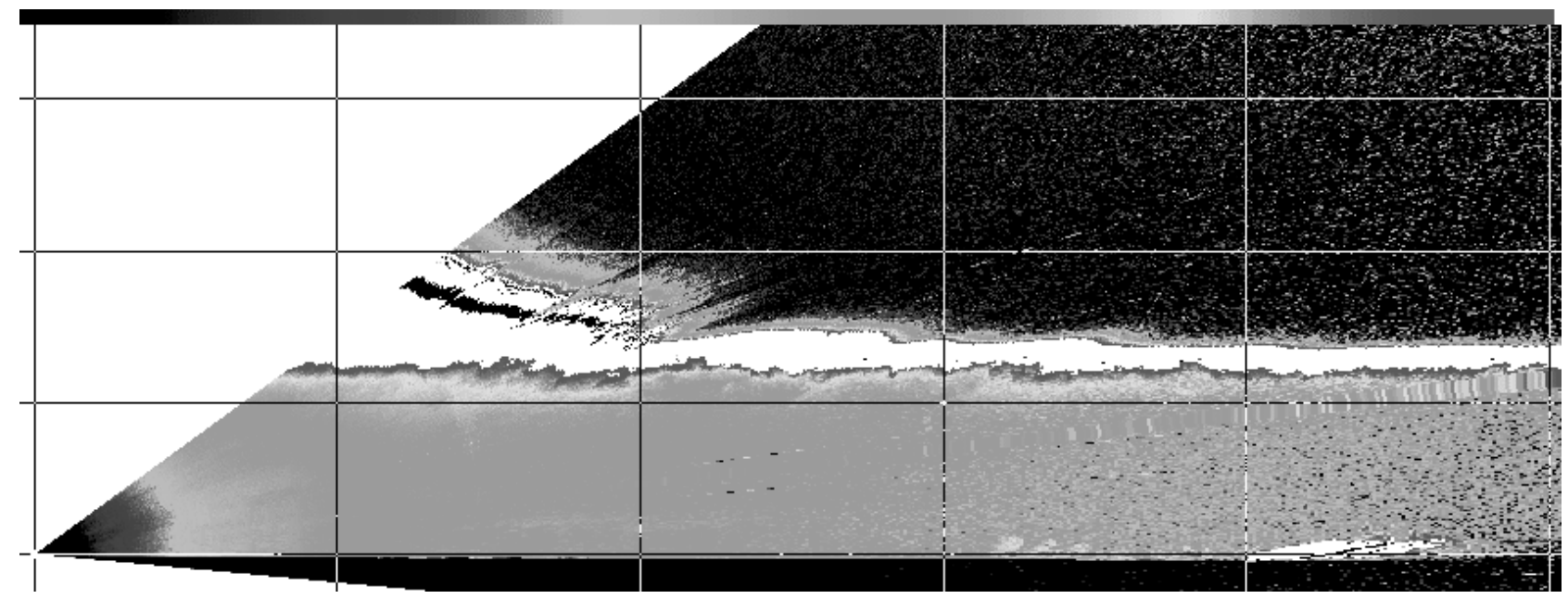

a

Tme: 12:04:50 - 12:14:20 23.06.1999 (JD 174)

Lat: 52.88 - 53.23 Long: -9.54 -10.04

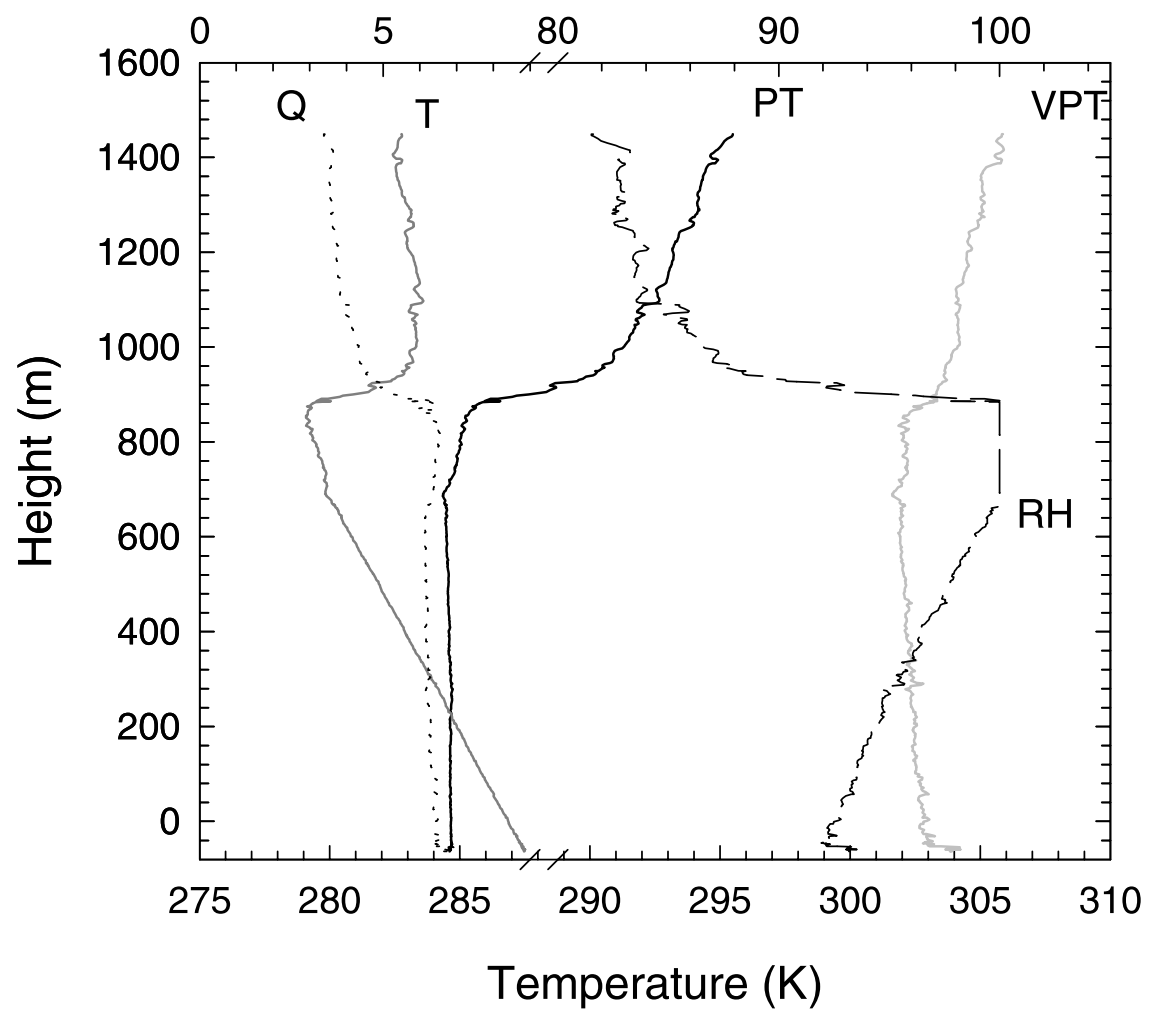

b

Figure 4. Boundary layer structure from lidar and airplane measurements on JD 174 (23 June 1999). (a) Vertical lidar scan at 1106 UTC. Horizontal and vertical scales are $1000 \mathrm{~m} / \mathrm{div}$ and $500 \mathrm{~m} / \mathrm{div}$. The attenuated atmospheric volume backscatter coefficients are color coded, with a scale for $\log [\mathrm{S}(\mathrm{R})]$ ranging from -7.0 (purple) to -5.6 (red) following the order of the colors in the rainbow. Black refers to values of $\log [S(R)]$ smaller than -7.0 , and white refers to values larger than $-5.6 \log \left(\mathrm{m}^{-1} \mathrm{sr}^{-1}\right)$. (b) Profiles of temperature ( $T$, in $\mathrm{K}$ ), potential temperature (PT, in $\mathrm{K})$, specific humidity ( $\mathrm{Q}$, in $\mathrm{g} \mathrm{kg}^{-1}$ ), virtual potential temperature (VPT, in $\mathrm{K}$ ) and relative humidity (RH, in\%) measured with the U.K. Meteorological Research Flight Hercules C-130 near Mace Head between 1204 and 1214 UTC. 


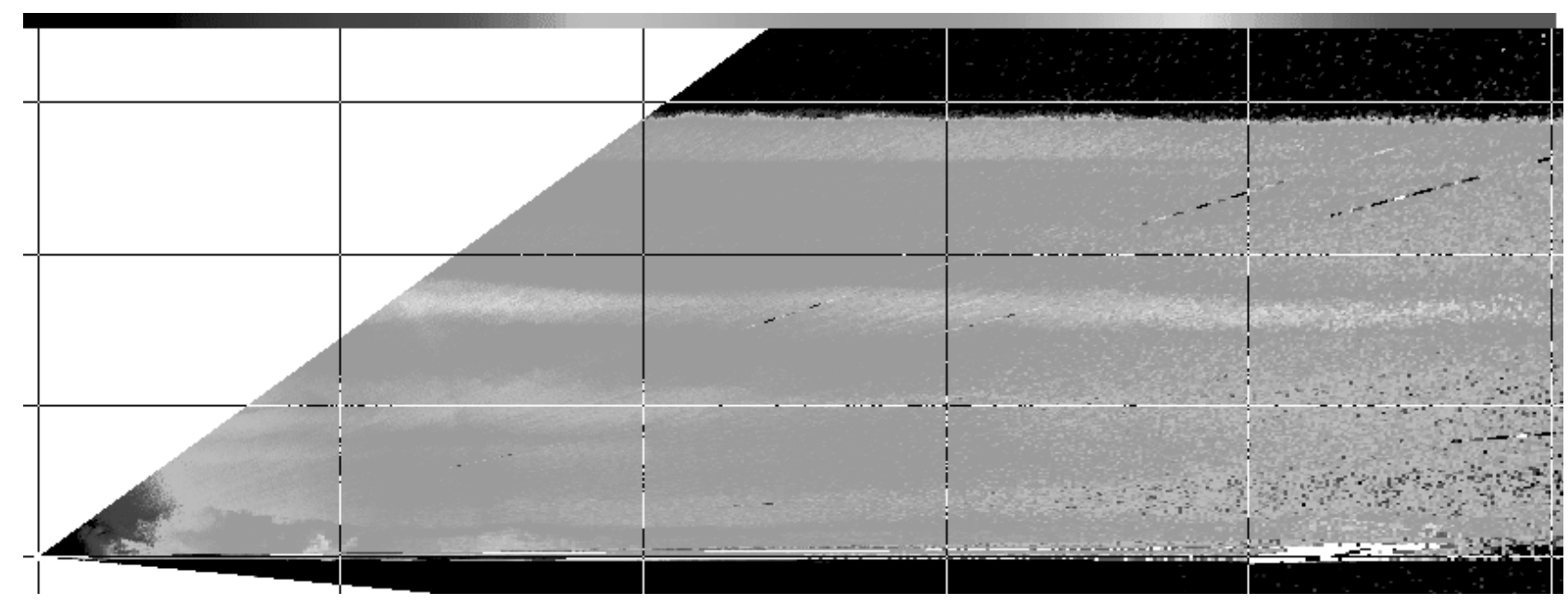

a

Tme: 12:04:06 - 12:13:36 25.06.1999 (JD 176)

Lat: $52.91-53.29$ Long: $-9.59-9.907$

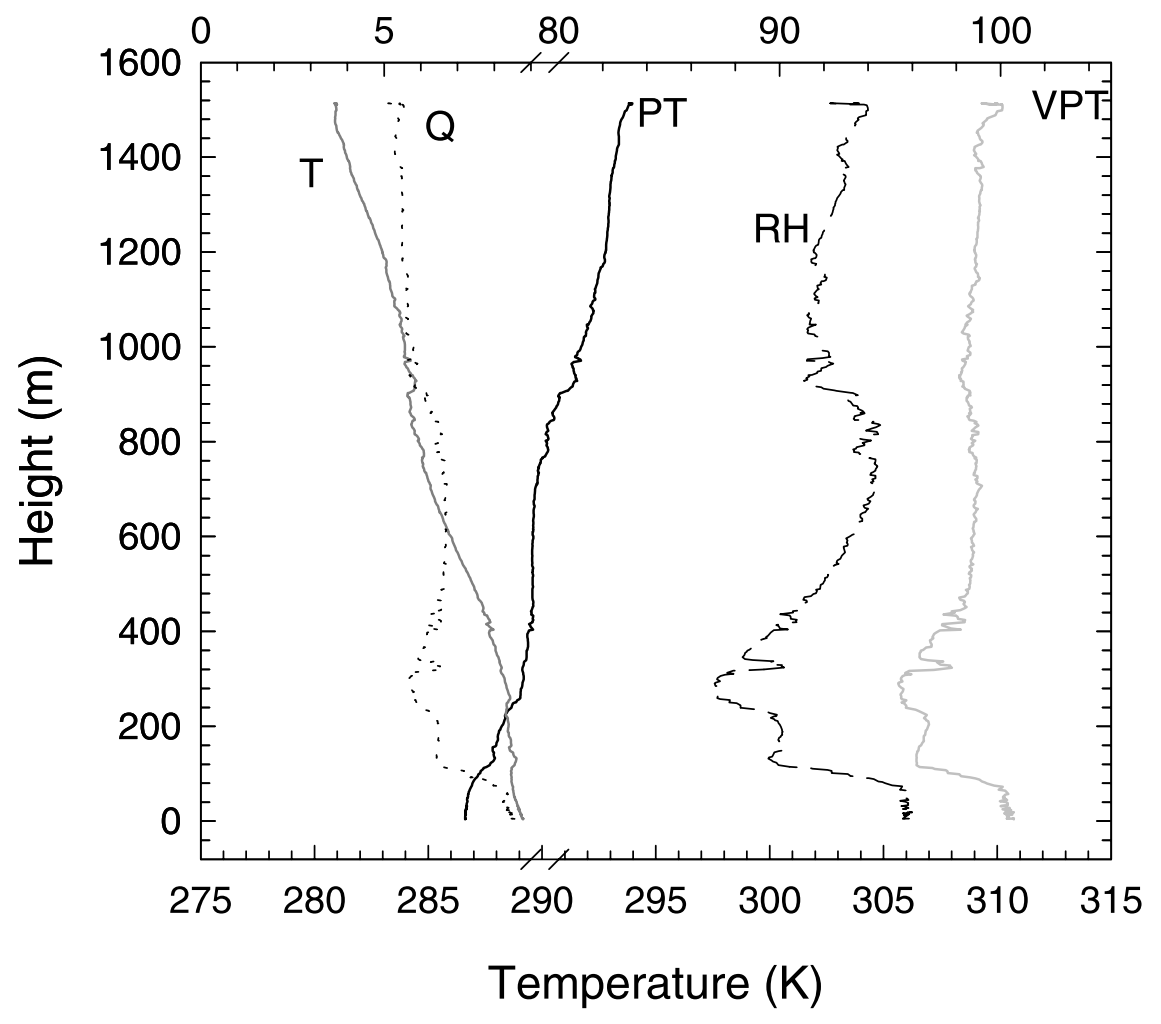

b

Figure 5. As Figure 4 for JD 176 (25 June 1999). Meteorological Research Flight Hercules C-130 measurements were made between 1204 and 1213 UTC; the LIDAR scan was made at 1206 UTC. 


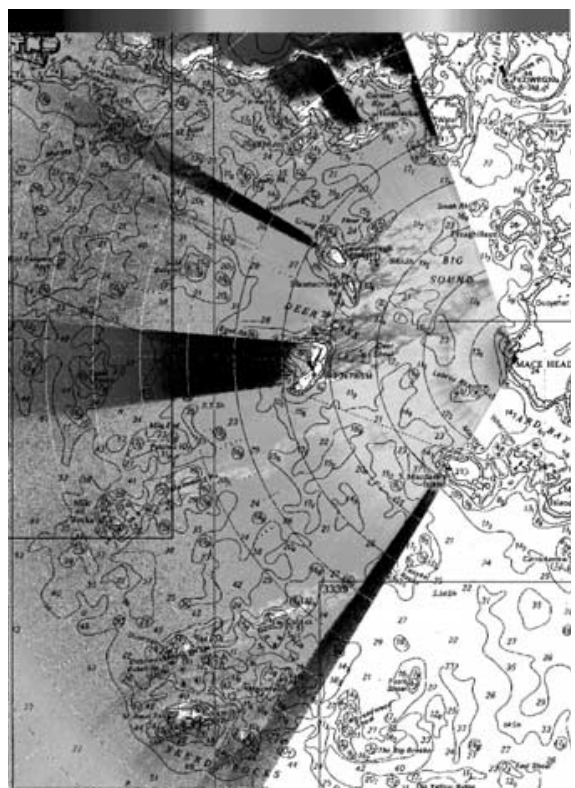

a

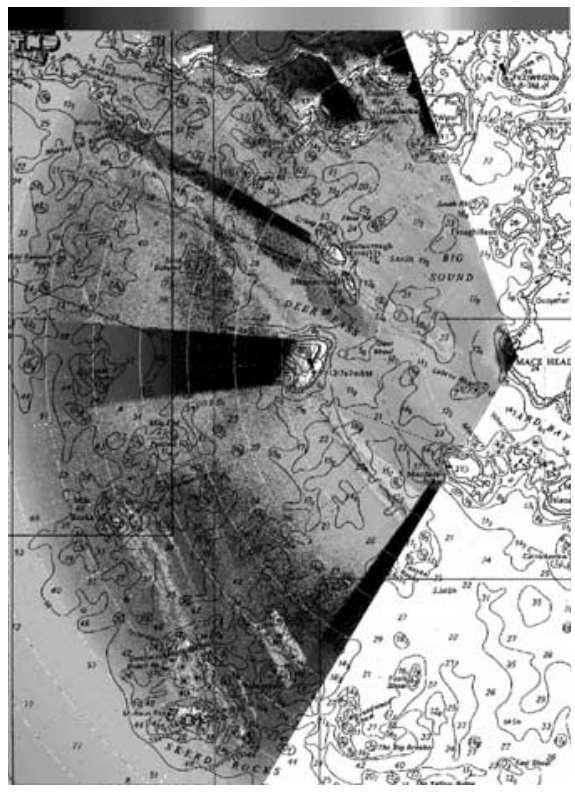

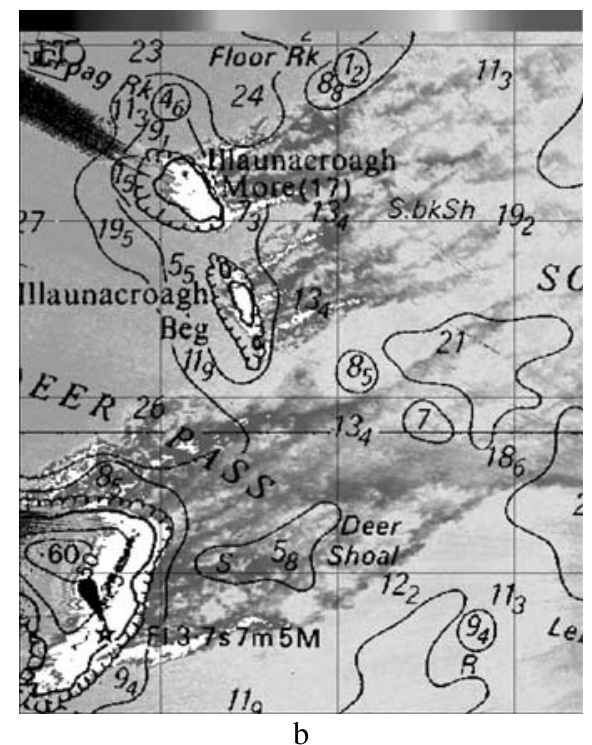

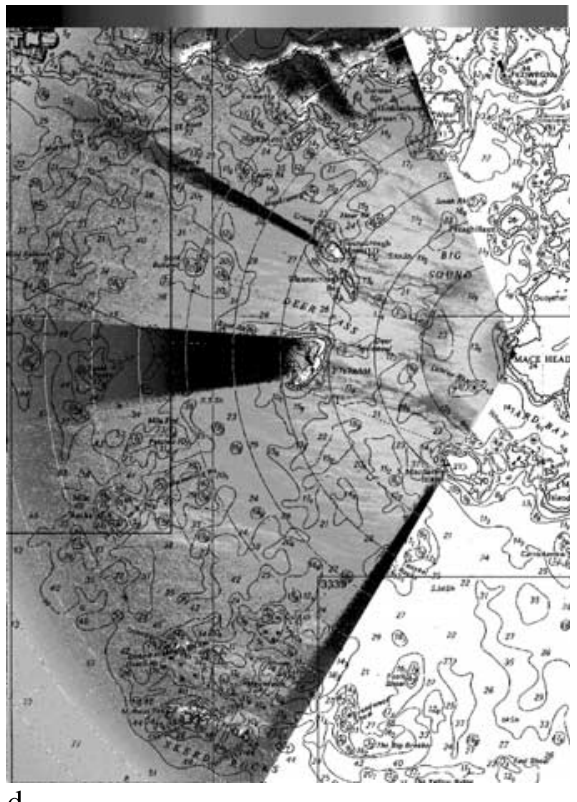

d

Figure 6. False color representations of the attenuated atmospheric volume backscatter coefficients obtained from horizontal lidar scans, projected over part of the map of Mace Head. Maps are oriented $\mathrm{S}-\mathrm{N}$. The lidar is situated in the origin of the circle segments near the text "MACE HEAD" (middle right). The distance between the circle segments in all figures is $1 \mathrm{~km}$. The grid in Figure $6 \mathrm{~b}$ is $1 \times 1 \mathrm{~km}^{2}$. The data show aerosol plumes generated at various island and rocks in the North Atlantic as red and yellow areas with enhanced backscatter intensities. The attenuated atmospheric volume backscatter coefficients are color coded, with a scale for $\log [\mathrm{S}(\mathrm{R})]$ following the order of the colors in the rainbow. The scale ranges ranging from -7.0 (purple) to an upper value that is different for each figure for optimum resolution Black refers to values smaller than $-7.0 \log \left(\mathrm{m}^{-1} \mathrm{sr}^{-1}\right)$, and white refers to values larger than the indicated maximum.

from an elevation angle of $+36^{\circ}$ down to $-5^{\circ}$ and only lidar data falling within the frame of the chosen window are presented in the figures. The first part of the lidar data (the dark segment in left corner of the triangle) are from within the crossover range interval of the lidar system, as explained in section 2.2. The beginning of the dark segment below the first horizontal range indicator is the sea surface. Structure near the sea surface at ranges between 4.2 and $4.7 \mathrm{~km}$ are discussed below (this structure is also observed in Figures 6 and 7).

[27] Figure 4a shows a relatively well-mixed boundary layer ending in a cloud deck at a height of about $600 \mathrm{~m}$, identified from the high scattering indicated by the white 


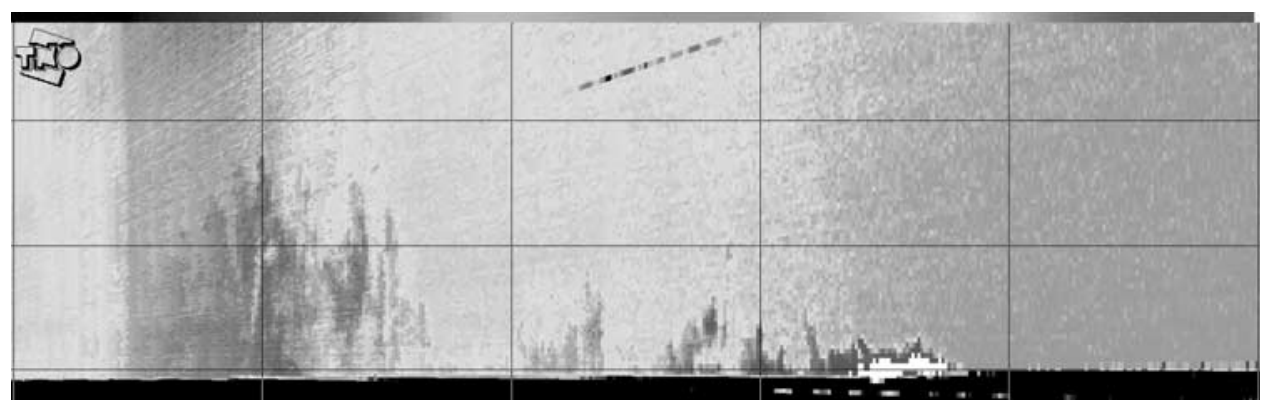

a

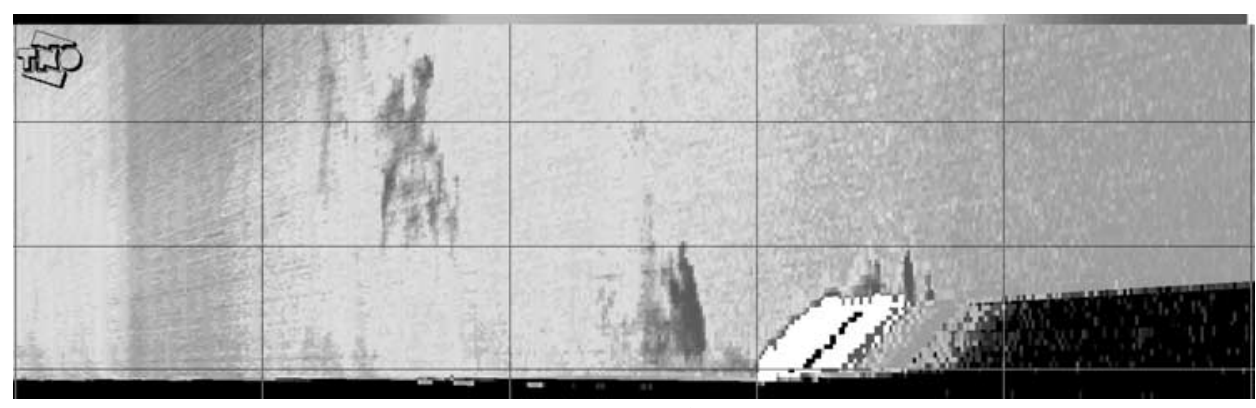

b

Figure 7. False color presentation of the attenuated atmospheric volume backscatter in a vertical plane between Mace Head and the island Croaghnakeela showing the vertical extent and transport of aerosol plumes generated by waves breaking on the island. The vertical scale is $100 \mathrm{~m} / \mathrm{div}$. Aerosol is transported over Croaghnakeela, which is visible as the white spot due to the very high reflection on the island. Data measured on JD 172 (21 June 1999). (a) Scan over the south part of Croaghnakeela at 2106 UTC. (b) Scan over the central part of Croaghnakeela at 2110 UTC. The attenuated atmospheric volume backscatter coefficients are color coded, with a scale for $\log [\mathrm{S}(\mathrm{R})]$ ranging from -7.0 (blue) to -5.3 (red) following the order of the colors in the rainbow. Black refers to values of $\log [\mathrm{S}(\mathrm{R})]$ smaller than -7.0 , and white refers to values larger than $-5.3 \log \left(\mathrm{m}^{-1} \mathrm{sr}^{-1}\right)$.

area. Due to the presence of the closed cloud deck it is not possible to determine the depth of the PBL. Just below the cloud the attenuated atmospheric volume backscatter coefficient increases due to increasing relative humidity causing cloud particle growth. The lidar signal vanishes rapidly inside the cloud due to extinction. From levels higher than $650-700 \mathrm{~m}$ no signal is received and the layer is colored black.

[28] Figure 5a shows a layered structure up to a capping inversion just below $1500 \mathrm{~m}$ where the lidar signal vanishes abruptly. At least 8 layers are visible, with a very shallow LAS in the lower $50-100 \mathrm{~m}$.

\subsubsection{Comparison With In Situ Measurements}

[29] Independent measurements of the structure of the lower atmospheric boundary layer are available from the C-130 airborne measurements (section 2.3). It is noted that simultaneous collocated lidar and airborne measurements were not possible because the lidar is not eye safe and could not be used when the aircraft was within $10 \mathrm{~km}$ from the station. Additionally, it is impossible to take vertical profiles at one location from an aircraft due to it being a moving platform. Typically, for every $1000 \mathrm{~m}$ covered in the vertical, this vertical extent corresponds to $30 \mathrm{~km}$ in the horizontal. Results presented from the in situ and lidar measurements were obtained within one hour or less.

[30] The vertical variation of potential temperature and specific humidity in Figure $4 \mathrm{~b}$ are textbook examples of a well-mixed atmosphere capped by a strong inversion. The figure shows a very well-mixed boundary layer up to cloud base at $650-700 \mathrm{~m}$, and very strong temperature and humidity gradients across the capping inversion at about $900 \mathrm{~m}$. The relative humidity data indicate a cloud with a thickness of 100-150 m. The layered structures, observed by the lidar and shown in Figure 4a, and the C-130 data, shown in Figure 4b are similar at the lowest altitudes, although the lidar observation indicates a somewhat lower cloud base.

[31] Also the second example, Figure 5b, shows a complex multilayered structure in good agreement with the lidar measurements. The measured vertical variations of potential temperature and specific humidity clearly show the atmospheric structure with a well-mixed layer near the surface up to about $100 \mathrm{~m}$, above which the potential temperature continues to increase up to about $400 \mathrm{~m}$. The latter indicates stable stratification that reduces vertical mixing. Hence the specific humidity is variable in this layer, and also the attenuated atmospheric volume backscatter coefficients show some structure. Between 400 and $800 \mathrm{~m}$ both the potential temperature and the specific humidity are constant; that is, the layer is well mixed. The relative humidity increases with altitude, and due to particle growth also the attenuated atmospheric volume backscatter coefficients increase up to a maximum at about $850-900 \mathrm{~m}$. Similarly, also at higher altitudes concomitant variations in potential 
temperature, specific humidity and attenuated atmospheric volume backscatter coefficients are observed, up to the maximum height of about $1500 \mathrm{~m}$ for which observations are available. The values of the relative humidity in the various layers indicate that in neither of them saturation occurs and hence cloud formation is not likely.

[32] The lower inversion observed during the airplane measurements is included in Figure 2. Although good agreement in PBL layering and structure was observed between the lidar and aircraft measurements, the inversion levels were not always observed at exactly the same heights. This variability is most likely caused by spatial and temporal variations in the PBL structure. As mentioned before, it was not possible to take lidar and airborne measurements simultaneous at the same location. Nevertheless, very encouraging agreement is seen between the in situ and remotely sensed measurements.

\subsection{Production and Dispersion of Locally Generated Aerosol Plumes}

\subsubsection{Spatial Distributions of Aerosol Particles:} Dispersion of Plumes Produced by Breaking Waves

[33] Spatial distributions of aerosol particles were studied by scanning the lidar in a horizontal plane over the water in westerly directions from $210^{\circ}$ to $340^{\circ}$ (angles measured with respect to north). After processing, the results were projected over the map of Mace Head. Examples of such scans are presented in Figure 6. The lidar was situated on the right-hand side in the origin of the equidistant circle segments indicating the range to the lidar. The colors in this figure correspond, as before, to the value of the attenuated atmospheric volume backscatter coefficient $S(R)$ as defined in equation (2). The white patches in the figure are caused by strong reflections of the laser light from the main land (to the north) and from the islands in the bay. Dark areas behind the islands indicate the regions from where no atmospheric signal can be received due to blocking of the laser pulse by the island structure. The difference in color between shadowed and adjacent nonshadowed areas thus indicates the scattering from atmospheric aerosol particles and molecules.

[34] Figure 6a illustrates plumes encountered on JD 172 of 1999 (21 June) under southwesterly airflow, wind speed was $4 \mathrm{~m} \mathrm{~s}^{-1}$. Very prominent are the aerosol plumes produced in the surf at the shorelines of Croaghnakeela (the large island $4 \mathrm{~km}$ to the west of Mace Head) and the two Illaunagroagh islands approximately $1 \mathrm{~km}$ north of Croaghnakeela. These plumes are about $2 \mathrm{~km}$ wide and can be followed to the edge of the scan, i.e., over a distance of at least $5 \mathrm{~km}$. Also the aerosol plumes generated by waves breaking on Scerd Rocks at distances between 7 and $10 \mathrm{~km}$ southwest of Mace Head are clearly visible, over a distance of at least $4 \mathrm{~km}$. The value of the attenuated atmospheric volume backscatter inside the plume, at a distance of about $500 \mathrm{~m}$ from this island, is enhanced by about a factor of three.

[35] Magnified detail of the plumes around Croaghnakeela is shown in Figure 6b. This image contains not merely enlargements, but represents real data. Figure $6 \mathrm{~b}$ clearly shows that the plume is generated over the whole width of the island and is composed of many smaller plumes. The intensities of the light backscattered from the plumes decrease with distance from the source, indicating that the concentrations of the aerosol particles decrease. This is mainly due to vertical dispersion of the aerosol particles, as discussed below based on evidence from vertical scans.

[36] The generation of such intense aerosol plumes in the surf of the islands west of Mace Head appears to be no exception, at least based on the frequency of observation during the two PARFORCE experiments. Other examples are presented in Figures $6 \mathrm{c}$ and $6 \mathrm{~d}$, for different wind situations. Figure $6 \mathrm{c}$ shows results that were obtained in NW wind with a speed of $3 \mathrm{~m} \mathrm{~s}^{-1}$. The appearance of the plumes in Figure $6 \mathrm{c}$ is quite different from that of the plumes shown in Figures 6a and 6d. Likely this is caused by differences in the direction and energy of the waves, which affect the resulting surf or, alternatively, atmospheric stratification which influences plume dispersion. At least five plumes with a length of more than $4 \mathrm{~km}$ can be distinguished from Croaghnakeela. The plumes from the Illaunagroagh islands are observed over a horizontal distance of at least $5 \mathrm{~km}$. Also the coastline of the main land produces much aerosol. Furthermore, intensive plumes are observed to originate from the rocks southwest of Mace Head, at distances between 8 and $10 \mathrm{~km}$. On this day, the attenuated atmospheric volume backscatter coefficient inside the plumes was enhanced with respect to the background by approximately one order of magnitude. The values of the attenuated atmospheric volume backscatter coefficient inside the plume decrease slowly with distance to the source due to vertical dispersion of the aerosol. At a distance of $2 \mathrm{~km}$ downwind, the enhancement with respect to the background is a factor 5 and at $4 \mathrm{~km}$ downwind from the generation region, the attenuated atmospheric volume backscatter coefficient inside the plume is only about a factor of two higher than the background value.

[37] The results presented in Figure $6 \mathrm{~d}$ were obtained on JD 178 of 1999 (27 June) in westerly wind with a speed of $8 \mathrm{~m} \mathrm{~s}^{-1}$. The attenuated atmospheric volume backscatter coefficients inside the plumes are similar to previously observed values, but the "background" attenuated atmospheric volume backscatter coefficients are higher due to the surface production of sea spray aerosol by breaking wind waves. The value of the attenuated atmospheric volume backscatter coefficient inside the plume at $500 \mathrm{~m}$ from the island is about a factor of 2.5 enhanced with respect to the background. At $4 \mathrm{~km}$ down wind from the source the attenuated atmospheric volume backscatter coefficients is reduced to half this value.

[38] Another feature observed in Figure 6d are plumes originating from breaking wind waves, visible as very narrow and slightly lighter colored lines. They are visible over several kilometers.

\subsubsection{Vertical Dispersion of Aerosol Plumes}

[39] The vertical dispersion of freshly generated plumes of sea spray aerosol was frequently observed during RHI operation of the lidar and is illustrated in Figure 7. Two examples are shown, of the attenuated atmospheric volume backscatter coefficients in vertical planes between Mace Head and Croaghnakeela (identified by the white spot caused by reflection from the south-coast of the island), respectively over the south point and the center of the island. These figures are based on data such as shown in Figure 4, but to better visualize processes near the sea surface the horizontal and vertical scales are magnified. 
[40] In Figure 7a, aerosol plumes, which were presumably generated in the surf on the west side of Croaghnakeela and advected across the island, are visible above and downwind (east) from the island. Apart from these advected plumes, also other, lower, plumes are visible on the down wind side. The explanation for the different plume heights could be that the lower plumes are generated by surf on the down wind side of the island due to refracted waves. This explanation is supported by the results from the vertical scan over the highest point of Croaghnakeela presented in Figure $7 \mathrm{~b}$. These show very clearly that plumes are generated at the down wind side of the island, with initial heights of $20-30 \mathrm{~m}$, growing to almost $300 \mathrm{~m}$ over a horizontal distance of $2 \mathrm{~km}$. The atmospheric attenuated volume backscatter coefficient inside the plume is about a factor of 1.5 enhanced with respect to the background.

\section{Discussion and Conclusions}

[41] The primary reason for the use of the lidar during PARFORCE experiments was to determine the depth of the boundary layers. The PBL structure was observed to vary from a single layer well-mixed structure to multilayered structure in which the LAS height was observed to vary from $100 \mathrm{~m}$ to more than $2000 \mathrm{~m}$. Often the PBL depth would initially decrease in the morning and increase in the afternoon. At times, the boundary layer height was observed to increase from about $600 \mathrm{~m}$ to $1200 \mathrm{~m}$ over a period of a few hours. One-dimensional profiling indicated significant variation in PBL height over timescales of tens of seconds.

[42] The structure of the PBL determined from the lidar data compares reasonably with available airborne data. Examples have been presented showing the similarity between backscatter structure and the structure determined from temperature and humidity measurements. It gives credit to the lidar measurements that the meteorological features, e.g., the complex boundary layer structure with multiple separated layers, are observed both in the lidar and in the meteorological profiles. This confirms earlier reports [e.g., Melfi et al., 1989; Carnuth and Trickl, 2000] that the lidar can be used to characterize the boundary layer structure. The advantage of a lidar is that it can potentially be used 24 hours per day, at relatively low cost. The time series in Figures 2 and 3 show that the PBL structure is quite variable and evolves throughout the day.

[43] The lidar also revealed significant primary aerosol plumes produced by waves breaking in the surf zone and at open sea. Vertical scans showed that plumes were generated both at the back of the islands (upwind) and on the other side of the island (at the lee). They were subsequently transported by the wind and could be observed to more than $10 \mathrm{~km}$ down wind from the source. Additionally, the lidar revealed that these plumes, generated with initial heights of some tens of meters, were vertically mixed to many hundreds of meters while transported over only a few kilometers. At these mixing heights, the sea spray could significantly influence cloud microphysics and development.

[44] Taking advantage of the lidar system calibration and the stability of the laser, approximate values for the attenuated backscatter coefficients could be obtained. Inside the plumes close to the source region values of $3-5 \times 10^{-6}$ $\mathrm{m}^{-1} \mathrm{sr}^{-1}$ were observed, independent of the wind speed (results were presented for wind speeds of 3, 4 and $8 \mathrm{~m} \mathrm{~s}^{-1}$ ). This is between 2 and 10 times higher than outside the plumes, i.e., in the "background" that includes molecules, and aerosol generated by breaking wind waves which is thus wind speed dependent. The background attenuated atmospheric volume backscatter coefficient in the highest wind speed is only a factor of 2-3 smaller than inside the plumes.

[45] The influence of the background renders it difficult to quantify the effect of locally generated plumes on the concentrations at Mace Head in relation to wind direction and wind speed. In particular because during transport from the islands to the Mace Head station, vertical dispersion causes dilution of the primary aerosol, which brings the concentrations close to background levels. Hence the influence on the concentrations measured at Mace Head is relatively small, if any. An attempt to quantify this effect from direct measurements of aerosol concentrations at Mace Head, based on differences in concentrations between selected wind directions, showed no clear correlation. Also there was no obvious concentration enhancement when the wind was from the directions of the islands. At low wind speed, the concentrations of super-micron aerosol particles at Mace Head exhibited variability of not more than a factor of 2 , and less in elevated wind speeds, although this cannot be directly linked to the offshore plumes. The concentrations of sub-micron aerosol particles are not affected [Kleefeld et al., 2002], in good agreement with other studies of surf aerosols [de Leeuw et al., 2000].

[46] The observations as regards the initial plume heights and their further evolution is in good agreement with other observations of aerosol plumes generated in the surf zone at beaches on the east and west coasts of the USA. Lidar studies undertaken at Wallops Island by Hooper and Martin [1999] show initial plume heights of circa $25 \mathrm{~m}$, in a wind speed of $5 \mathrm{~m} \mathrm{~s}^{-1}$. Similar results from later experiments, over the surf zone in Duck (North Carolina, USA), were well reproduced by an aerosol transport model [Vignati, 1999; Vignati et al., 2001]. This model used results from aerosol measurements over the surf zone by de Leeuw et al. [2000] on Scripps Pier in La Jolla (San Diego, California, USA). The analysis of these measurements showed that the maximum height attained by the surf-produced aerosol is about $20 \mathrm{~m}$ at very low wind speeds, and more than $50 \mathrm{~m}$ at wind speeds approaching $9 \mathrm{~m} \mathrm{~s}^{-1}$. These results compare favorably with lidar observations of the surf produced aerosol in offshore wind during the same experiment [Gathman and Smith, 1997].

[47] Also the increase of the aerosol concentrations and the attenuated atmospheric volume backscatter coefficients inside the plumes, with respect to background values, compare reasonably well with results reported in the literature. The lidar measurements by Hooper and Martin [1999] show backscatter increases over the surf of two orders of magnitude, and the analysis of aerosol measurements by de Leeuw et al. [2000] reveal an increase of the concentrations over the surf zone by up to two orders of magnitude. These numbers apply for measurements directly over or in the immediate vicinity of the surf zone, whereas the current measurements were made hundreds of meters downwind from the surf zone where the concentrations, and 
thus also the attenuated atmospheric backscatter coefficients, were significantly diminished.

[48] The relatively constant values of the attenuated atmospheric volume backscatter coefficients inside the plumes near the source, as compared to the wind speed dependent background values, are a clear indication of the different processes that lead to the generation of sea spray aerosol. At open sea the breaking intensity of wind waves increases with wind speed, whereas the energy in the waves breaking at the coastline, islands and rocks is mainly determined by swell that is generated by remote wind fields.

[49] Acknowledgments. The PARFORCE project was supported by the European Commission DG XII under contract ENV4-CT97-0526. TNO-FEL participated with balancing funds from the Netherlands Ministry of Defense. The U.K. Meteorological Research Flight Hercules C-130 was supported by the EU project STAAARTE (Scientific Training and Access to Aircraft for Atmospheric Research Throughout Europe). Gerard Jennings and Gerry Spain of the National University of Ireland, Galway, Ireland, are acknowledged for the hospitality at the Mace Head Atmospheric Research Station. Michael Geever provided the logistic support during the experiments. Stimulating discussions with Keith Bigg during the experiments are acknowledged. We are grateful for the support received from Leo Cohen from TNO-FEL before, during and after the experiments.

\section{References}

Ackermann, J., Two-wavelength lidar inversion algorithm for a two-component atmosphere, Appl. Opt., 36, 5134-5143, 1997.

Albrecht, B. A., C. S. Bretherton, D. W. Johnson, W. H. Schubert, and A. Shelby Frisch, The Atlantic Stratocumulus Transition ExperimentASTEX, Bull. Am. Meteorol. Soc., 76, 889-904, 1995.

American National Standards Institute, Inc., American national standard for the safe use of lasers, Rep. ANSI Z136.1-1986, 120 pp., Am. Natl. Standards Inst., New York, 1993.

Bates, T. S., B. J. Huebert, J. L. Gras, B. Griffiths, and P. A. Durkee, The International Global Atmospheric Chemistry (IGAC) Project's First Aerosol Characterization Experiment (ACE 1): Overview, J. Geophys. Res., 103, 16,297-16,318, 1998.

Carnuth, W., and T. Trickl, Transport studies with the IFU three-wavelength aerosol lidar during the VOTALP Mesolcina experiment, Atmos. Environ., 34, 1425-1434, 2000.

Collis, R. T. H., LIDAR: A new atmospheric probe, Q. J. R. Meteorol. Soc., 92, 220-230, 1966.

Cooper, D. I., W. E. Eichiner, D. B. Holtkamp, R. R. Karl, C. R. Quick, W. Dugas, and L. Hipps, Spatial variability of water vapor turbulent transfer within the boundary layer, Boundary Layer Meteorol., 61, 389-405, 1992

de Leeuw, G., F. P. Neele, M. Hill, M. H. Smith, and E. Vignati, Sea spray aerosol production by waves breaking in the surf zone, J. Geophys. Res., $105,29,397-29,409,2000$.

Eichinger, W. E., D. I. Cooper, F. L. Archuletta, D. Hof, D. B. Holtkamp, R. R. Karl, C. R. Quick, and J. Tiee, Development of a scanning solarblind water Raman lidar, Appl. Opt., 18, 3923-3932, 1994.

Eichinger, W. E., D. I. Cooper, P. R. Forman, J. Griegos, M. A. Osborn, D. Richter, L. L. Tellier, and R. Thornton, The development of a scanning Raman water vapor lidar for boundary layer and tropospheric observations, J. Atmos. Oceanic Technol., 16, 1753-1766, 1999.

Eloranta, E. W., and D. K. Forrest, Volume-imaging lidar observations of the convective structure surrounding the flight path of a flux-measuring aircraft, J. Geophys. Res., 97, 18,383-18,393, 1992.

Eloranta, E. W., J. M. King, and J. A. Weinman, The determination of wind speeds in the boundary layer by monostatic lidar, J. Appl. Meteorol., 14, $1485-1489,1975$.

Fernald, F. G., B. M. Herman, and J. A. Reagan, Determination of aerosol height distribution by lidar, J. Appl. Meteorol., 11, 482-489, 1972.

Gathman, S. G., and M. H. Smith, On the nature of surf generated aerosol and their effect on electro-optical systems, in Propagation and Imaging Through the Atmosphere, edited by L. R. Bissonnette and C. Dainty, pp. 2-13, Int. Soc. for Opt. Eng., Bellingham, Wash., 1997.

Goldsmith, J. E. M., F. H. Blair, S. E. Bisson, and D. D. Turner, Turn-key Raman lidar for profiling atmospheric water vapor, clouds, and aerosols, Appl. Opt., 37, 4979-4990, 1998.

Hagelberg, C. R., D. I. Cooper, C. L. Winter, and W. E. Eichinger, Scale properties of microscale convection in the marine surface layer, J. Geophys. Res., 103, 16,897-16,907, 1998.

Hitschfeld, W., and J. Bordan, Errors inherent in the radar measurement of rainfall at attenuating wavelengths, J. Meteorol., 11, 58-67, 1954.

Hoell, C., C. D. O'Dowd, S. R. Osborne, and D. W. Johnson, Timescale analysis of marine boundary layer aerosol evolution: Lagrangian case studies under clean and polluted cloudy conditions, Tellus, Ser. B, 52, $423-438,2000$

Hooper, W. P., and E. W. Eloranta, Lidar measurements of wind in the planetary boundary layer: The method, accuracy, and results from joint measurements with radiosonde and kytoon, J. Clim. Appl. Meteorol., 25, $990-1001,1986$.

Hooper, W. P., and L. U. Martin, Scanning lidar measurements of surf-zone aerosol generation, Opt. Eng., 38, 250-255, 1999.

Hooper, W. P., J. E. James, and R. J. Lind, Lidar observations of turbulent vortex shedding by an isolated topographic feature, Boundary Layer Meteorol., 80, 95-108, 1996.

International Electrotechnical Commission (IEC), Radiation safety of laser products, equipment classification, requirements and user's guide, IEC Stand. Publ. 825, Geneve, 137 pp., 1984.

Jennings, S. G., C. D. O'Dowd, T. C. O'Connor, and F. M. McGovern, Physical characteristics of the ambient aerosol at Mace Head, Atmos. Environ., Part A, 25, 557-562, 1991.

Jennings, S. G., M. Geever, and T. C. O'Connor, Coastal CCN measurements at Mace Head with enhanced concentrations on strong winds, Atmos. Res., 46, 243-252, 1998.

Johnson, D. W., S. R. Osborne, R. Wood, K. Suhre, P. K. Quinn, T. Bates, M. O. Andreae, K. J. Noone, P. Glantz, B. Bandy, J. Rudolph, and C. D. O'Dowd, Observations of the evolution of the aerosol, cloud and boundary layer characteristics during the first ACE-2 Lagrangian experiment, Tellus, Ser. B, 52, 348-374, 2000.

Kleefeld, C., S. O'Reilly, S. G. Jennings, G. J. Kunz, G. de Leeuw, P. Aalto, E. Becker, and C. D. O'Dowd, The relative contribution of sub and super micron particles to aerosol light scattering on the marine boundary layer (MBL), J. Geophys. Res., 107, doi:10.1029/2000JD000262, in press, 2002.

Klett, J. D., Stable analytical inversion solution for processing lidar returns, Appl. Opt., 20, 211-220, 1981.

Kovalev, V. A., Sensitivity of the lidar solution to errors of the aerosol backscatter-to-extinction ratio: Influence of a monotonic change in the aerosol extinction coefficient, Appl. Opt., 34, 3457-3462, 1995.

Kunkel, K. E., E. W. Eloranta, and S. T. Shipley, Lidar observations of the convective boundary layer, J. Appl. Meteorol., 16, 1306-1311, 1977.

Kunz, G. J., Vertical atmospheric profiles measured with lidar, Appl. Opt., 22, 1955-1957, 1983.

Kunz, G. J., Transmission as input boundary value for an analytical solution of the single scatter lidar equation, Appl. Opt., 35, 3255-3260, 1996.

Kunz, G. J., Two-wavelength lidar inversion algorithm, Appl. Opt., 38 , 1015-1020, 1999.

Martin, G. M., D. W. Johnson, P. R. Jonas, D. P. Rogers, I. M. Brooks, and R. W. Barlow, Effects of airmass type on the interaction between warm stratocumulus and underlying cumulus clouds in the marine boundarylayer, Q. J. R. Meteorol. Soc., 123, 849-882, 1997.

McGovern, F. M., S. G. Jennings, T. C. O'Connor, and P. G. Simmonds, Aerosol and trace gas measurements during the Mace Head experiment, Atmos. Environ., 30, 3891-3902, 1996.

Measures, R. M., Laser Remote Sensing: Fundamentals and Applications, 510 pp., John Wiley, New York, 1984.

Melfi, S. H., J. D. Spinhirne, S.-H. Chou, and S. P. Palm, Lidar observations of vertically organized convection in the planetary boundary layer over the ocean, J. Clim. Appl. Meteorol., 24, 806-821, 1985.

Melfi, S. H., D. Whitemen, and R. Ferrare, Observation of atmospheric fronts using Raman lidar moisture measurements, J. Appl. Meteorol., $28,789-806,1989$.

Nakane, H., and Y. Sasano, Structure of a sea-breeze front revealed by scanning lidar observations, J. Meteorol. Soc. Jpn., 64, 787-791, 1986.

O'Dowd, C. D., New Particle Formation and Fate in the Coastal Environment (PARFORCE), IGACtivities Newsl. Int. Global Atmos. Chem. Prog., 18, 3-6, 1999.

O'Dowd, C. D., et al., A dedicated study of New Particle Formation and Fate in the Coastal Environment (PARFORCE): Overview of objectives and achievements, J. Geophys. Res., 107, doi:10.1029/2001JD000555, in press, 2002a.

O'Dowd, C. D., et al., Coastal new particle formation: Environmental conditions and aerosol physicochemical characteristics during nucleation bursts, J. Geophys. Res., 107, doi:10.1029/2000JD000206, in press, $2002 \mathrm{~b}$.

Osborne, S. R., D. W. Johnson, R. Wood, B. J. Bandy, M. O. Andrae, C. D. O'Dowd, P. Glantz, and K. Noone, Observations of the evolution of the aerosol, cloud and boundary layer dynamic and thermodynamic charac- 
teristics during the second Lagrangian experiment of ACE-2, Tellus, Ser. $B, 52,375-400,2000$.

Piironen, A. K., and E. W. Eloranta, Accuracy analysis of wind profiles calculated from volume imaging lidar data, J. Geophys. Res., 100, 25,559-25,567, 1995.

Piironen, A. K., and E. W. Eloranta, Three-dimensional images of cirrus clouds derived from volume imaging lidar observations, in Proceedings of the18th International Laser Radar Conference (ILRC), edited by A. Ansmann et al., pp. 79-82, Springer-Verlag, New York, 1996.

Platt, C. M. R., Remote sounding of high clouds, I, Calculation of visible and infrared optical properties from lidar and radiometer measurements, J. Appl. Meteorol., 18, 1130-1143, 1979.

Potter, J. F., Two-frequency lidar inversion technique, Appl. Opt., 26, $1250-1256,1987$.

Raes, F., T. S. Bates, F. McGovern, and M. Vanliedekerke, The second Aerosol Characterisation Experiment (ACE-2): Overview, Tellus, Ser. B, $52,111-149,2000$

Rogers, D. P., D. W. Johnson, and C. A. Friehe, The stable internal boundary layer over a coastal sea, I, Airborne measurements of the mean and turbulence structure, J. Atmos. Sci., 52, 667-683, 1995.

Sasano, Y., H. Shimizu, N. Sugimoto, I. Matsui, N. Takeuchi, and M. Okuda, Diurnal variation of the atmospheric planetary boundary layer observed by a computer-controlled laser radar, J. Meteorol. Soc. Jpn., 58, $143-148,1980$.

Sasano, Y., H. Shimizu, and N. Takeuchi, Convective cell structures revealed by Mie laser radar observations and image data processing, Appl. Opt., 21, 3166-3169, 1982a.

Sasano, Y., H. Hirohara, T. Yamasaki, H. Shimizu, N. Takeuchi, and T. Kawamura, Horizontal wind vector determination from the displacement of aerosol distribution patterns observed by a scanning lidar, $J$. Appl. Meteorol., 21, 1516-1523, 1982b.

Schols, J. L., and E. W. Eloranta, Calculation of area-averaged vertical profiles of the horizontal wind velocity from volume-imaging lidar data, J. Geophys. Res., 97, 18,395-18,407, 1992.

Schotland, R. M., Remote ground-based observing systems, in Handbook of Applied Meteorology, edited by D. D. Houghton, pp. 361-379, John Wiley, New York, 1985.

Steyn, D. G., M. Baldi, and R. M. Hoff, The detection of mixed layer depth and entrainment zone thickness from lidar backscatter profiles, J. Atmos. Oceanic Technol., 16, 953-959, 1999.

Stull, R. B., An Introduction to Boundary Layer Meteorology, 666 pp., Kluwer Acad., Norwell, Mass., 1988.

Vignati, E., Modelling interactions between aerosols and gaseous compounds in the polluted marine atmosphere, Ph.D. thesis, Rep. Risø-R1163(EN), 133 pp., Risø Natl. Lab., Roskilde, Denmark, 1999.

Vignati, E., G. de Leeuw, and R. Berkowicz, Modeling coastal aerosol transport and effects of surf-produced aerosols on processes in the marine atmospheric boundary layer, J. Geophys. Res., 106, 20,225-20,238, 2001.

Weinman, J. A., Derivation of atmospheric extinction profiles and wind speed over the ocean from a satellite-borne lidar, Appl. Opt., 27, 3994-4001, 1988.

E. Becker, BP Chemicals Ltd., HRTC/DL10, Saltend Lane, Hedon HU12 8DS, UK. (edo.becker@sunderland.ac.uk)

G. de Leeuw and G. Kunz, TNO Physics and Electronics Laboratory, P.O. Box 96864, N-2509 JG, The Hague, Netherlands. (deleeuw@fel.tno.nl; kunz@fel.tno.nl)

C. D. O’Dowd, Department of Physical Sciences, University of Helsinki, P.O. Box 64, FIN-00014 Helsinki, Finland. (colin.odowd@cmas.demon. co.uk) 